\title{
Differences between semantic profiles of the action tendencies linked to emotion words in achievement and unspecified general contexts, defined by Colombian Spanish native speakers
}

\section{Jason A. Chavarría ${ }^{1}$, Johny Villada Zapata $^{1}$ \& Liliana Chaves Castaño ${ }^{1}$}

${ }^{1}$ Department of Psychology, University of Antioquia, Medellín

\section{Colombia}

Correspondence: Jason A. Chavarría Tapias. Department of Psychology, University of Antioquia, Medellín, Colombia. Street 67 \#53-108, square 9, office 252. E-mail: jason.chavarria@udea.edu.co

(C) Education \& Psychology I+D+i and Ilustre Colegio Oficial de la Psicología de Andalucía Oriental (Spain) 


\begin{abstract}
Introduction. We investigated the meaning of sixteen achievement emotion words — anger, anxiety, boredom, contentment, despair, disappointment, frustration, guilt, hope, hopelessness, joy, pride, relief, sadness, shame, and surprise-, specifically in terms of their action tendencies component, through a modified version of the CoreGRID questionnaire. Our aim was to identify in which cases the achievement context modifies the semantic profiles of each emotion word, specifically in terms of their action tendencies component, as compared to an unspecified general context.
\end{abstract}

Method. Forty-one participants (22 females; $M_{\text {age }}=21.8, S D=3.5$ ), and another group of thirty-six participants ( 21 females; $M_{a g e}=20.42, S D=2.8$ ), rated the likelihood of eighteen action tendencies to be part of the meaning of each emotion word in an achievement context condition and in a general context condition, respectively.

Results. In both conditions, Cronbach's Alpha ranged from 0.95 to 0.98 . Data analysis revealed statistically significant differences for every emotion investigated, suggesting an influence of context in their semantic profile.

Discussion. The discussion of these results is centered mainly around data from other studies that were interested in the motivational component of emotions, since there is a lacking of research on semantic profiles of achievement emotions. Finally, we make suggestions on directions for future research and inform of the limitations of our study.

Keywords: achievement emotions, semantic profiles, action tendencies, achievement context, CoreGRID questionnaire. 


\section{Diferencias entre los perfiles semánticos de las tendencias a la acción relacionadas con términos emocionales en contextos de logro y no es- pecificados, definidos por hablantes nativos de español colombiano}

\section{Resumen}

Introducción. Investigamos los significados de dieciseis palabras de emociones de logro -ira, ansiedad, aburrición, satisfacción, desesperación, decepción, frustración, culpa, esperanza, desesperanza, alegría, orgullo, alivio, tristeza, vergüenza y sorpresa-, específicamente en términos de su componente de tendencias a la acción, por medio de una versión modificada del cuestionario CoreGRID. Nuestro objetivo fue identificar los casos en que el contexto de logro modifica los perfiles semánticos de cada término emocional, específicamente en términos de su componente de tendencias a la acción, en comparación con un contexto general no especificado.

Método. Cuarenta y un participantes (22 mujeres; $M_{\text {edad }}=21.8, S D=3.5$ ), y otro grupo de treinta y seis participantes ( 21 mujeres; $M_{e d a d}=20.42, S D=2.8$ ), valoraron la posibilidad de que dieciocho tendencias a la acción hicieran parte del significado de cada término emocional en una condición de contexto de logro y en un contexto general, respectivamente.

Resultados. En ambas condiciones, el Alpha de Cronbach estuvo entre 0.95 y 0.98 . El análisis de los datos reveló diferencias estadísticamente significativas para cada emoción, lo cual sugiere una influencia del contexto en sus perfiles semánticos.

Discusión. La discusión de estos resultados se centra principalmente en los datos de otros estudios que se interesaron en el componente motivacional de las emociones, puesto que hace falta investigación sobre los perfiles semánticos de las emociones de logro. Finalmente, hacemos sugerencias para estudios futuros e informamos las limitaciones de nuestro estudio.

Palabras clave: emociones de logro, perfiles semánticos, tendencias a la acción, contexto de logro, cuestionario CoreGRID. 


\section{Introduction}

Emotions are ubiquitous in all kinds of contexts. Therefore, much to the interest of education, sports, work, and psychology, emotions also pertain to achievement contexts. The term achievement refers to "the quality of activities or their outcomes as evaluated by some standard of excellence" (Heckhausen, 1991, as cited in Pekrun, Frenzel, Goetz, \& Perry, 2007, p. 15). Emotions related directly to achievement activities and achievement outcomes are known as achievement emotions (Pekrun et al., 2007), and may have effects on cognitive resources (e.g., resources availability; attention focus; flow), interest and motivation (e.g., increasing or decreasing intrinsic motivation; strengthening motivation to invest effort in avoiding failure), strategies of learning (e.g., rigid vs. creative), self- or external regulation of learning, and academic achievement.

According to Pekrun's (2006) control-value theory (CVT), achievement emotions can be distinguished by their valence, by the physiological activation they imply, and by identifying their object focus: activity emotions (e.g., enjoyment, boredom, frustration, and anger) pertain to ongoing achievement-related activities; and outcome emotions pertain to the outcomes of these activities (Pekrun, 2006), and can be either prospective/anticipatory (e.g., hope and anxiety) or retrospective (e.g., pride and shame). Appraisal dimensions, such as goal relevance, causal attribution, outcome probability, coping potential, and normative significance, among others, are given a pivotal role in the causation of emotional states. The CVT of achievement emotions "provides an integrative framework for analyzing the antecedents and effects of emotions experienced in achievement and academic settings" (Pekrun, 2006, p. 315). According to this approach, appraisals of control and values are crucial for the arousal of achievement emotions. Importantly, two groups of appraisals are identified (Pekrun, 2006): (1) subjective control (i.e., perceived causal influence of an agent) over achievement activities and their outcomes; and (2) subjective values (i.e., perceived valences) of these activities and outcomes. Different patterns of these appraisals elicit different achievement emotions.

Although the appraisal component of emotion has a central role in the control-value theory, the adaptive function of emotion regarding the preparation and direction of action should also be considered in achievement contexts. Every emotion is associated with action tendencies that motivate, organize and guide behavior in adaptive or maladaptive ways (Izard, 1991); the outcome depends on how productive is the resulting behavior according to the 
goals of the subject. Since its beginnings in primitive organisms, emotion prepares for approach and withdrawal reactions, and in more complex organisms emotions have been perfected in differentially preparing more specific behavior based on an ongoing evaluation of the situation facilitated by the emotion process (Fontaine \& Scherer, 2013). Different patterns of appraisal are thus expected to be elicited in different contexts, and to determine action tendencies at least partly (Frijda, Kuipers, \& ter Schure, 1989). In achievement contexts, action tendencies may result beneficial or detrimental to success or failure. Moreover, whether in achievement contexts or in any other context, as noted by Fontaine and Scherer (2013), behavioral responses linked to emotions may be different and "depend on [...] the physical and cultural constraints of the situation as well as on the regulation mechanisms used by the person at a particular point in time" (p. 171). The appraisals of such constraints can influence the experience of the action tendencies in a given context, and whether or not they are expressed in observable behavior.

The study of achievement emotions increases scientific knowledge about the extent to which emotions influence outcomes like engagement, life-long learning, and social climate in classrooms and educational institutions (Pekrun, 2006), as well as in competitions, and in working contexts. Information on these subjects may lead decision making when trying to influence subjects' emotions, fostering or reducing them on the basis of goal conduciveness. Unfortunately, there is only a small amount of publications about research on achievement emotions in the context of Spanish-speaking countries. For example, in Argentina, Paoloni and Vaja (2013), interviewed university students about their emotions before, during, and after an academic exam, and found that self-efficacy expectations promoted by the preparation prior to the exam and teacher's reassurance and feedback were associated with the experience of corresponding positive emotions. Sánchez-Rosas (2013) studied the relations between achievement emotions and control-value appraisals about academic help-seeking and academic social self-efficacy, and found that perceived benefit of help-seeking correlated positively with the experience of pride and enjoyment, and negatively with shame, while perceived social self-efficacy showed positive correlations with enjoyment and hope, and correlated negatively with shame and anxiety. And finally, González, Donolo and Rinaudo (2009) analyzed the relations between achievement goals and class-related emotions, and found that subjects whose goals focused on avoiding failure and poor performance experimented anxiety and shame, subjects characterized with lack of motivation experimented enjoyment, pride and hope the less, and subjects who reported multiple approach goals (increasing mastery and 
having the best performance in class) experienced pride and enjoyment the most, but also anxiety and shame, which theoretically may positively motivate them to work hard. In Spain, research has focused instead on teachers and students' emotions in science education with an interest of fostering positive emotions towards sciences such as physics and chemistry (Mellado et al., 2014). In Colombia, there is a lack of studies about achievement emotions.

One of the challenges that emerge from intercultural research of emotion refers to the translation of emotion words and to what extent the equivalent terms share the same psychological meaning (Russell, 1991). Typically, in order to investigate emotions, studies analyze a person's subjective account of their emotional experience. Instruments that assess emotions generally ask respondents to describe their experience using emotion words. However, to successfully study the emotions experienced by participants, it is important that researchers understand the meaning given to emotion words by native speakers, given that it captures what a community thinks is pertinent in emotional experiences. As noted by Scherer, Shuman, Fontaine, and Soriano (2013), there's evidence that "people differ with respect to their verbal ability and richness of vocabulary, which makes it difficult to compare reports across individuals or to rely on their accuracy" (p. 281). Traditionally, self-report of subjective experience of emotions presents participants with forced-choice items, or give priority to how emotions are felt (feeling component) based on three dimensions — valence (pleasant-unpleasant), arousal (calm-excited), and tension (tense-relaxed) - that arrange to form a differentiated feeling state. The limitation of the latter procedure consists in that, when it comes to emotional sharing, a dimensional metric is not the best alternative, since people seldom communicate their emotional states in degrees of valence, arousal and tension (Scherer et al., 2013).

An alternative procedure that attempts to overcome the limitations of self-report comes from the Componential Process Model (CPM), which assumes that emotions differ in their specific response profiles across five components: appraisal, bodily reactions, feelings, expressions, and action tendencies. These components form the emotional process, which Scherer (2013) briefly describes as follows:

[...] the event and its consequences are appraised with a set of criteria on multiple levels of processing, producing a motivational effect or action tendency that often changes or at least modifies the status quo. Specifically, the appraisal results and the concomitant motivational changes will produce efferent effects in the autonomic nervous system (in the form of somatovisceral changes) and the somatic nervous system (in the 
form of motor expression in face, voice, and body). All of these components, appraisal results, action tendencies, somatovisceral changes, and motor expressions are centrally represented and constantly fused in a multimodal integration area (with continuous updating as events and appraisals change). Parts of this central integrated representation may then become conscious and subject to assignment to fuzzy emotion categories, as well as being labeled with emotion words, expressions, or metaphors. (p. 13)

For the GRID paradigm, grounded in the CPM, the meaning of emotion words relates to the specific pattern of appraisal and response changes in all components that are implied when using a specific word to describe an emotion episode. This approach allows studies to ask participants to describe the typical eliciting and response characteristics in the five emotion process components that would warrant the description of a person's emotional state with an specific label (Scherer, 2013). As a result, a certain degree of agreement should be found among speakers, because, as put by Van den Eede and Fontaine (2013), "the references to the five components do not fluctuate at whim, but show replicable meaning structures across languages and cultural groups" (p. 301). This procedure is known as semantic grid profiles, because "the ratings on the component features for different emotions can be arranged in a grid with the respective emotion words as columns" (Scherer, 2013, p. 27). Different versions of a GRID questionnaire were constructed following this paradigm with the purpose of identifying the meaning of emotion words.

Identifying the semantic profiles of emotion words in Colombian Spanish-speakers is justified by the assertion that by using such terms, people of a specific culture may refer to all or any part of the emotion process and which component they do refer to may well be culturally and individually idiosyncratic (Johnson-Laird y Oatley, 1989). In the case of achievement emotions, an specific culture may significantly shape an individual's beliefs and motivations by providing culturally shared meanings about what is socially important, what various circumstances imply for personal wellbeing, and which emotions are appropriate under those circumstances (Smith y Lazarus, 1990), which overall suggest that appropriate action tendencies vary accordingly. Gentsch et al. (in press) also investigated the effect of achievement contexts on the semantic profile of emotion words, in the German language, but found evidence of change in the action tendencies component only for "anxiety". (Their study suggests a rather stronger effect of context on the feature profiles along the appraisal component, not only for anxiety, but also for most of the emotion words they investigated.) Nevertheless, it is 
still important to study if the same case applies for emotion words in another language and cultural environment.

\section{Aims and hypothesis}

Characterizing achievement emotions into their components using a CPM approach will be helpful for further studies that, ultimately, seek the enhancement of student academic experience, of performance in competition and work settings, and improvement of achievement settings, under the premise that subjects' emotions "can be positively influenced by fostering their perceptions of competence and control over activities and outcomes" in achievement contexts (Pekrun, 2006, p. 334). The present study attempts to identify the effect of the achievement context on the semantic profiles of the action tendencies of achievement emotions, with the hypothesis that the semantic profile has a complex relationship with context. This research is done under the assumption that the knowledge about the meaning that people ascribe to emotion words, when describing their experience, may benefit further studies about the functions and motivational components of emotions pertaining to situations of success or failure.

\section{Method}

\section{Participants}

Participants were recruited from two second year courses of the undergraduate program of Psychology at the University of Antioquia. Students were sent an invitation via email to participate in a controlled web study to which they could access with a personal password. Those interested were assigned one of two conditions, one of which prompted them to define emotion terms used when referring to an achievement context (Condition 1), whereas the other condition referred to an unspecified general context (Condition 2). Seventy-seven participants successfully completed the study: Forty-one students (22 females; $M_{\text {age }}=21.8, S D=$ 3.5) under Condition 1, and thirty-six students ( 21 females; $M_{\text {age }}=20.42, S D=2.8$ ) under Condition 2.

\section{Instruments}

For Condition 1, participants responded the Achievement Emotion CoreGrid questionnaire (henceforth AECG), originally developed by Loderer, Gentsch, Pekrun, and Scherer (2015). The Colombian Spanish version was constructed by adapting the English version of 
the questionnaire following a translation-backtranslation process, whereby the instrument was first translated from English to Spanish by the authors, and then back-translated into English by a second translator. Discrepancies between the resulting versions were solved through discussion using a committee approach.

For Condition 2, participants responded the adjusted version of the Colombian Spanish CoreGRID questionnaire (CG), originally developed by Scherer, Fontaine, and Soriano (2013). The Colombian Spanish version of the instrument was constructed by first following the translation-backtranslation process described above, resulting in one Spanish version of the CoreGRID, and later adjusting this instrument so that the items were the same as the AECG's minus the achievement context. Therefore, whereas the AECG asked participants to define emotion words used to describe an emotional experience related to success or failure, the CG made no reference to a specific context.

The two questionnaires presented participants with eighty-four emotion features belonging to the different components of emotions, such as appraisals, bodily reactions, expressions (vocal, facial and postural), action tendencies, and feelings. Respondents defined the meaning of sixteen emotion words, as commonly used by native speakers of Spanish, by rating the likelihood of each emotion feature occurring when a particular emotion word is used by a person to describe their emotional experience (related to success or failure, in the case of the achievement context condition). In order to do this, a nine-point Likert scale was provided, where $1=$ "Extremely likely", 2 = "Very likely", 3 = "Unlikely", 4 = "Somewhat unlikely", 5 = "Neither likely nor unlikely", 6 = "Somewhat likely", 7 = "Likely", $8=$ "Very likely", and $9=$ "Extremely likely". The emotion words rated were ira (anger), sorpresa (surprise), alegría (joy), orgullo (pride), culpa (guilt), vergüenza (shame), tristeza (sadness), satisfacción (contentment), decepción (disappointment), ansiedad (anxiety), esperanza (hope), alivio (relief), desesperanza (hopelessness), aburrimiento (boredom), frustración (frustration), and desesperación (despair). Figure 1 shows a schematic representation of how an item was presented in the window of an Internet browser. For the purpose of answering the research questions previously expressed, only the data analyses for behavioral tendencies are described below. 
Figure 1. Schematic representation of the structure of all eighty-four items from both questionnaires

\section{Procedure}

The teacher of the courses facilitated the lists of students enrolled in each course. Students were assigned a condition in the order they appeared in the list, so that one half of each course belonged to the achievement context condition and the other half belonged to an unspecified context condition. Interested students were instructed to assist to the Faculty's computer lab at course hours, where they had to access the questionnaire with their personal password. Participants completed their assigned questionnaire in two sessions, each one lasting approximately one hour, rating eight emotion words per session. Participants in the achievement condition were also asked to complete a set of additional scales distributed between both sessions. All participants were informed of their rights to abstain from participating and to withdraw from the study at any given time without having to justify their decision, without entailing any negative consequence. Consent forms informed participants about the procedure and length of the study, anonymity and confidentiality.

\section{Data analysis}

The databases were exported to the Statistical Package for the Social Sciences (SPSS, version 21), where the matrix was arranged in such a way that the rows represented the eighty-four emotion features and the columns represented participant by word combinations. In order to clean up the databases, participant by word combinations for which a participant did not differentiate enough (i.e., they chose more than fifty-eight times the same response category) were removed. Six observations in Condition 1 and two in Condition 2 were removed following this criterion. Furthermore, interrater reliabilities per emotion word were 
calculated, and participant by word combinations with a corrected-item-total correlation below .20 were removed. Three observations in Condition 1 and two in Condition 2 were removed following this criterion. Data analysis was carried out on the basis of all respondents with a corrected-item-total correlation above .20. Participant's agreement on the meaning profile of each emotion word was established using Cronbach's Alpha.

Shapiro-Wilk normality tests per emotion word revealed that the data are not from a normally distributed population (for all cases, $p<0.05$ ). Accordingly, the Mann-Whitney $U$ test was used to analyze the median differences in behavioral tendencies for each emotion between conditions. The meaning profile of each emotion was identified by calculating the medians obtained per emotion feature.

\section{Results}

Interrater agreement on the meaning profile of each emotion word was satisfactory, Cronbach's Alpha ranged from 0.95 to 0.98 in both conditions. This section presents only statistically significant differences between the achievement context and the unspecified general context per emotion word.

\section{Anger}

When a person uses the word anger to describe their emotional experience, it is unlikely that they wanted that situation to last or be repeated and wanted to comply with someone else's wishes, but it is less so if they refer to a general context. It is more likely that they wanted to oppose someone or something and wanted to tackle the situation in a general situation than in an achievement situation. Interestingly, it is somewhat likely that they wanted to do nothing in a context of success and failure while that is very unlikely in a general context. And it is also likely that they lacked the motivation to pay attention to what was happening in an achievement situation, while it is only somewhat likely in a general context. These results are shown in Table 1.

Table 1 .

Statistically significant differences between achievement and general context for Anger

\begin{tabular}{|c|c|c|c|c|}
\hline \multirow{2}{*}{ Feature } & \multicolumn{2}{|c|}{ Median } & \multirow{2}{*}{$\begin{array}{c}\text { Mann Whit- } \\
\text { ney's U }\end{array}$} & \multirow{2}{*}{ Sig. } \\
\hline & Condition 1 & Condition 2 & & \\
\hline wanted the ongoing situation to last or be & 2 & 1 & 498.5 & 0.009 \\
\hline
\end{tabular}
repeated 
Differences between semantic profiles of the action tendencies linked to emotion words in achievement and unspecified general contexts, defined by Colombian Spanish native speakers

wanted to comply with someone else's

wishes

wanted to do nothing

lacked the motivation to pay attention to

what was happening

wanted to oppose someone or something

wanted to tackle the situation

wanted to sing and dance
2

6

7

8

7

1
1

$$
2
$$

9

8

1
415.5

382

520

499.5

545.5

506
0.000

0.000

0.024

0.006

0.045

0.005

\section{Anxiety}

Only one statistically significant difference was found between the two conditions. When using the word anxiety to describe their experience, it is likely that the person wanted to run away in any direction when in an achievement context $(M d n=7)$, but it is more likely in a general context $[(M d n=8), U=451, p=0.004]$.

\section{Boredom}

Differences between conditions were observed in achievement-related features. It is unlikely that the person wanted to try harder and wanted to approach the task systematically if they experienced boredom in an achievement situation, but it is very unlikely in another context. Finally, it is somewhat likely that they wanted to try new or creative ways of approaching the task at hand when in an achievement situation, but it is very unlikely in another general context. Results are shown in Table 2.

Table 2.

Statistically significant differences between achievement and general context for Boredom

\begin{tabular}{|c|c|c|c|c|}
\hline \multirow{2}{*}{ Feature } & \multicolumn{2}{|c|}{ Median } & \multirow{2}{*}{$\begin{array}{l}\text { Mann Whit- } \\
\text { ney's } U\end{array}$} & \multirow{2}{*}{ Sig. } \\
\hline & Condition 1 & Condition 2 & & \\
\hline wanted to try harder & 3 & 2 & 502 & 0.012 \\
\hline $\begin{array}{l}\text { wanted to approach the task systematical- } \\
\text { ly }\end{array}$ & 3 & 2 & 415.5 & 0.000 \\
\hline $\begin{array}{l}\text { wanted to try new or creative ways of } \\
\text { approaching the task at hand }\end{array}$ & 4 & 2 & 382 & 0.000 \\
\hline
\end{tabular}

\section{Contentment}

Multiple statistically significant differences were found for contentment. They are shown in Table 3.

Table 3.

Statistically significant differences between achievement and general context for Contentment

\begin{tabular}{|c|c|c|c|c|}
\hline \multirow{2}{*}{ Feature } & \multicolumn{2}{|c|}{ Median } & \multirow{2}{*}{$\begin{array}{c}\text { Mann Whit- } \\
\text { ney's U }\end{array}$} & \multirow{2}{*}{ Sig. } \\
\hline & Condition 1 & Condition 2 & & \\
\hline wanted the ongoing situation to last or be & 8 & 9 & 523 & 0.011 \\
\hline
\end{tabular}

repeated 
wanted to stop what they were doing wanted to undo what was happening wanted to do nothing

lacked the motivation to pay attention to what was happening wanted to disappear or hide from others wanted to do damage, hit, or say something that hurts wanted to oppose someone or something wanted to run away in any direction wanted to sing and dance was able to concentrate on what was going on

$\begin{array}{lccc}2 & 1 & 456.5 & 0.002 \\ 2 & 1 & 457.5 & 0.001 \\ 2 & 1 & 440 & 0.002 \\ 2 & 1 & 421 & 0.001 \\ 2 & & \\ 2 & 1 & 490.5 & 0.005 \\ 4 & 1 & 298.5 & 0.000 \\ 2 & & & \\ 8 & 2 & 414.5 & 0.001 \\ 7 & 1 & 422 & 0.000 \\ & 9 & 369 & 0.000 \\ & 8 & 464.5 & 0.004\end{array}$

\section{Despair}

In a situation in which a person experiences despair, it is extremely likely that the person wanted to stop what they were doing, wanted to do damage, hit, or say something that hurts, and wanted to undo what was happening, and it is likely that they wanted to oppose someone or something, but it is less likely in an achievement context. And, while it is unlikely that they wanted that situation to last or be repeated, wanted to comply with someone else's wishes, and wanted to approach the task systematically, it is less likely if it is not an achievement situation. Differences are shown in Table 4.

Table 4.

Statistically significant differences between achievement and general context for Despair

\begin{tabular}{lcccc}
\hline \multirow{2}{*}{ Feature } & \multicolumn{2}{c}{ Median } & $\begin{array}{c}\text { Mann Whit- } \\
\text { ney's U }\end{array}$ & Sig. \\
\cline { 2 - 4 } $\begin{array}{l}\text { wanted the ongoing situation to last or be } \\
\text { repeated }\end{array}$ & 2 & 1 & 487 & 0.004 \\
wanted to stop what they were doing & 7 & 9 & 525.5 & 0.026 \\
wanted to undo what was happening & 8 & 9 & 462.5 & 0.003 \\
wanted to comply with someone else's & 4 & 2 & 501.5 & 0.015 \\
wishes & & & 412 & 0.001 \\
wanted to do damage, hit, or say some- & 7 & 9 & 489 & 0.009 \\
thing that hurts & & 8 & 510 & 0.015 \\
wanted to oppose someone or something & 7 & 2 & 522.5 & 0.017 \\
wanted to run away in any direction & 8 & 2 & 426.5 & 0.001
\end{tabular}
ly

\section{Disappointment}

For disappointment, while it is extremely likely that the person wanted to undo what was happening it is less likely under an achievement context. And it is more likely that they were able to concentrate on what was going on, wanted to overcome an obstacle, wanted to 
comply with someone else's wishes, and wanted the ongoing situation to last or be repeated when in a context related to success or failure. See Table 5.

Table 5.

Statistically significant differences between achievement and general context for Disappointment

\begin{tabular}{|c|c|c|c|c|}
\hline \multirow{2}{*}{ Feature } & \multicolumn{2}{|c|}{ Median } & \multirow{2}{*}{$\begin{array}{l}\text { Mann Whit- } \\
\text { ney's U }\end{array}$} & \multirow{2}{*}{ Sig. } \\
\hline & Condition 1 & Condition 2 & & \\
\hline $\begin{array}{l}\text { wanted the ongoing situation to last or be } \\
\text { repeated }\end{array}$ & 2 & 1 & 473 & 0.005 \\
\hline wanted to undo what was happening & 7.5 & 9 & 450.5 & 0.004 \\
\hline $\begin{array}{l}\text { wanted to comply with someone else's } \\
\text { wishes }\end{array}$ & 3.5 & 2 & 482 & 0.012 \\
\hline wanted to overcome an obstacle & 4 & 3 & 530.5 & 0.046 \\
\hline was able to concentrate on what was go- & 4 & 3 & 481.5 & 0.012 \\
\hline
\end{tabular}

ing on

\section{Frustration}

When a person says he or she experienced frustration, it is likely that they wanted to undo what was happening and wanted to oppose someone or something, but less likely if it was an achievement situation, whereas it is more likely that they wanted to sing and dance, wanted to approach the task systematically, and wanted the ongoing situation to last or be repeated in an achievement situation. See Table 6.

Table 6.

Statistically significant differences between achievement and general context for Frustration

\begin{tabular}{lcccc}
\hline \multirow{2}{*}{ Feature } & \multicolumn{2}{c}{ Median } & Mann Whit- & \multirow{2}{*}{ Sig. } \\
\cline { 2 - 3 } $\begin{array}{l}\text { wanted the ongoing situation to last or be } \\
\text { repeated }\end{array}$ & 2 & 1 & 522 & 0.012 \\
wanted to undo what was happening & 8 & 9 & 544 & 0.032 \\
wanted to oppose someone or something & 6 & 7 & 545.5 & 0.046 \\
wanted to sing and dance & 2 & 1 & 427.5 & 0.001 \\
wanted to approach the task systematical- & 4 & 2 & 494 & 0.011
\end{tabular}
$l y$

\section{Guilt}

For guilt, it is most likely that the person wanted to stop what they were doing and that they wanted to comply with someone else's wishes, but it is less likely in an achievement context. And it is very unlikely that they wanted to do damage, hit, or say something that hurts, but it is more likely an achievement situation. It is also more likely that, in the achievement situation, the person wanted the ongoing situation to last or be repeated. Table7. 
Table 7.

Statistically significant differences between achievement and general context for Guilt

\begin{tabular}{|c|c|c|c|c|}
\hline \multirow{2}{*}{ Feature } & \multicolumn{2}{|c|}{ Median } & \multirow{2}{*}{$\begin{array}{l}\text { Mann Whit- } \\
\text { ney's U }\end{array}$} & \multirow{2}{*}{ Sig. } \\
\hline & Condition 1 & Condition 2 & & \\
\hline $\begin{array}{l}\text { wanted the ongoing situation to last or be } \\
\text { repeated }\end{array}$ & 2 & 1 & 544 & 0.042 \\
\hline wanted to stop what they were doing & 7.5 & 8 & 532.5 & 0.045 \\
\hline $\begin{array}{l}\text { wanted to comply with someone else's } \\
\text { wishes }\end{array}$ & 5.5 & 7 & 493 & 0.017 \\
\hline $\begin{array}{l}\text { wanted to do damage, hit, or say some- } \\
\text { thing that hurts }\end{array}$ & 4 & 2 & 416 & 0.001 \\
\hline
\end{tabular}

Hope

When a person uses the word hope to describe their emotional experience, it is unlikely that the person wanted to stop what they were doing, and wanted to undo what was happening, but it is less likely in a context that may not involve achievement. Results are shown in Table 8.

Table 8.

Statistically significant differences between achievement and general context for Hope

\begin{tabular}{lcccc}
\hline \multirow{2}{*}{ Feature } & \multicolumn{3}{c}{ Median } & Mann Whit- \\
\cline { 2 - 3 } & Condition 1 & Condition 2 & ney's U & Sig. \\
\hline wanted to stop what they were doing & 3 & 2 & 520.5 & 0.033 \\
wanted to undo what was happening & 3 & 2 & 461 & 0.006 \\
wanted to run away in any direction & 2 & 2 & 481 & 0.010
\end{tabular}

\section{Hopelessness}

When referring to hopelessness, it is somewhat unlikely $(M d n=4)$ that the person wanted to comply with someone else's wishes, wanted to try new or creative ways of approaching the task at hand, and it is very unlikely $(M d n=2)$ that they wanted to sing and dance, in an achievement situation, but even less so in another contexts $[U=478.5, p=0.011$, $U=526.5, p=0.031$, and $U=519, p=0.032$, respectively $]$.

Joy

When a person uses the word Joy to describe their emotional experience, it is very unlikely that they wanted to stop what they were doing, to undo what was happening, to oppose someone or something and to do damage, hit, or say something that hurts, but it is more unlikely in an unspecified general context. See Table 9. 
Table 9.

Statistically significant differences between achievement and general context for Joy

\begin{tabular}{|c|c|c|c|c|}
\hline \multirow{2}{*}{ Feature } & \multicolumn{2}{|c|}{ Median } & \multirow{2}{*}{$\begin{array}{l}\text { Mann Whit- } \\
\text { ney's U }\end{array}$} & \multirow{2}{*}{ Sig. } \\
\hline & Condition 1 & Condition 2 & & \\
\hline $\begin{array}{l}\text { wanted the ongoing situation to last or be } \\
\text { repeated }\end{array}$ & 8 & 8 & 580 & 0.041 \\
\hline wanted to stop what they were doing & 2 & 1 & 534.5 & 0.027 \\
\hline wanted to undo what was happening & 2 & 1 & 539 & 0.027 \\
\hline $\begin{array}{l}\text { wanted to do damage, hit, or say some- } \\
\text { thing that hurts }\end{array}$ & 2 & 1 & 455.5 & 0.002 \\
\hline wanted to oppose someone or something & 3 & 2 & 395.5 & 0.000 \\
\hline
\end{tabular}

Pride

In an achievement situation in which a person experienced pride, it is somewhat likely that the person wanted to oppose someone or something $(M d n=6)$, whereas in another kind of situation, it is not $(M d n=2), U=244, p=0.000$. And it is more likely that they wanted to do damage, hit, or say something that hurts, in an achievement situation, while still being unlikely for both conditions [ $U=428, p=0.013]$.

\section{Relief}

Even being unlikely for both conditions, when a person says they felt relieved, it is less likely that they wanted to stop what they were doing, undo what was happening, do nothing, do damage, hit, or say something that hurts, disappear or hide from others and run away in any direction, in a situation different from achievement. See Table 10.

Table 10.

Statistically significant differences between achievement and general context for Relief

\begin{tabular}{|c|c|c|c|c|}
\hline \multirow{2}{*}{ Feature } & \multicolumn{2}{|c|}{ Median } & \multirow{2}{*}{$\begin{array}{l}\text { Mann Whit- } \\
\text { ney's U }\end{array}$} & \multirow{2}{*}{ Sig. } \\
\hline & Condition 1 & Condition 2 & & \\
\hline wanted to stop what they were doing & 3 & 2 & 520 & 0.023 \\
\hline wanted to undo what was happening & 2 & 1 & 511 & 0.015 \\
\hline wanted to do nothing & 3 & 2 & 520.5 & 0.023 \\
\hline wanted to disappear or hide from others & 2 & 2 & 547 & 0.041 \\
\hline $\begin{array}{l}\text { wanted to do damage, hit, or say some- } \\
\text { thing that hurts }\end{array}$ & 2 & 1 & 519 & 0.018 \\
\hline wanted to run away in any direction & 2 & 1 & 459 & 0.003 \\
\hline
\end{tabular}

\section{Sadness}

When a person experiences sadness in an achievement situation, it is more likely that he or she wanted to do damage, hit, or say something that hurts, than in any other situation. It is also more likely that they wanted to try harder and tackle the situation in an achievement context. However, it is not more likely that they wanted someone else to take the initiative, 
wanted to undo what was happening, and lacked the motivation to pay attention to what was happening if compared to another kind of situation. See Table 11.

Table 11.

Statistically significant differences between achievement and general context for Sadness

\begin{tabular}{|c|c|c|c|c|}
\hline \multirow{2}{*}{ Feature } & \multicolumn{2}{|c|}{ Median } & \multirow{2}{*}{$\begin{array}{l}\text { Mann Whit- } \\
\text { ney's U }\end{array}$} & \multirow{2}{*}{ Sig. } \\
\hline & Condition 1 & Condition 2 & & \\
\hline $\begin{array}{l}\text { wanted the ongoing situation to last or be } \\
\text { repeated }\end{array}$ & 2 & 1 & 371 & 0.000 \\
\hline wanted to undo what was happening & 7 & 8.5 & 434 & 0.001 \\
\hline wanted someone else to take the initiative & 6 & 8 & 465.5 & 0.005 \\
\hline $\begin{array}{l}\text { lacked the motivation to pay attention to } \\
\text { what was happening }\end{array}$ & 8 & 9 & 477 & 0.006 \\
\hline $\begin{array}{l}\text { wanted to do damage, hit, or say some- } \\
\text { thing that hurts }\end{array}$ & 6 & 3.5 & 433.5 & 0.002 \\
\hline wanted to tackle the situation & 3 & 2 & 471.5 & 0.005 \\
\hline wanted to sing and dance & 2 & 1 & 411 & 0.000 \\
\hline wanted to try harder & 3 & 2 & 505 & 0.015 \\
\hline
\end{tabular}

\section{Shame}

Multiple statistically significant differences were found for shame. They are shown in

Table 12.

Table 12.

Statistically significant differences between achievement and general context for Shame

\begin{tabular}{lcccc}
\hline \multirow{2}{*}{ Feature } & \multicolumn{2}{c}{ Median } & $\begin{array}{c}\text { Mann Whit- } \\
\text { ney's U }\end{array}$ & \multirow{2}{*}{ Sig. } \\
\cline { 2 - 4 } $\begin{array}{l}\text { wanted the ongoing situation to last or be } \\
\text { repeated }\end{array}$ & 1 & 1 & 587.5 & 0.033 \\
$\begin{array}{l}\text { wanted to stop what they were doing } \\
\text { wanted to do damage, hit, } \text { or say something }\end{array}$ & 8 & 9 & 514.5 & 0.015 \\
that hurts & 5 & 3 & 416 & 0.001 \\
wanted to sing and dance & 2 & 1 & 533 & 0.019
\end{tabular}

\section{Surprise}

Statistically significant differences for the emotion word surprise are shown in Table 13.

Table 13.

Statistically significant differences between achievement and general context for Surprise

\begin{tabular}{|c|c|c|c|c|}
\hline \multirow{2}{*}{ Feature } & \multicolumn{2}{|c|}{ Median } & \multirow{2}{*}{$\begin{array}{c}\text { Mann Whit- } \\
\text { ney's U }\end{array}$} & \multirow{2}{*}{ Sig. } \\
\hline & Condition 1 & Condition 2 & & \\
\hline $\begin{array}{l}\text { wanted to comply with someone else's } \\
\text { wishes }\end{array}$ & 5 & 4.5 & 453.5 & 0.008 \\
\hline wanted to do nothing & 5 & 3.5 & 496 & 0.034 \\
\hline wanted to sing and dance & 6 & 5 & 425 & 0.004 \\
\hline wanted to try harder & 5 & 5 & 476 & 0.015 \\
\hline
\end{tabular}


Differences between semantic profiles of the action tendencies linked to emotion words in achievement and unspecified general contexts, defined by Colombian Spanish native speakers

wanted to approach the task systematically

wanted to try new or creative ways of approaching the task at hand
5

6
4.5

5
388

399
0.001

0.002

\section{Discussion}

The study of the semantic profiles of achievement emotions is a new approach to the study of emotions in achievement settings. As such, there is a lack of information regarding this specific research interest, a direct antecedent being the research done by Loderer et al. (2015). Results from the present study show contextual differences in the semantic profiles of emotion's action tendencies described by Colombian Spanish speakers. Some of the differences can be interpreted as qualitatively relevant, whereas the others may pose a challenge for interpretation (e.g., differencing between "very" and "extremely" in response categories). Nevertheless, in the following section, results are compared with the knowledge from current research on achievement emotions, highlighting some of the issues that need more attention in future research. Given that Pekrun's (2006) CVT offers a three-dimensional taxonomy of achievement emotions, in which emotions can be grouped by their object focus, valence, and their effect (or degree of activation), in this section, analyses are presented according to their valence and effect in order to offer a better appreciation of the results.

\section{Positive activating emotions}

Results suggest that the effect of the achievement context in the semantic profiles of the emotions joy and hope consists on a tendency to maintain the activity that elicited such emotions. This can be explained by the effects that both joy and hope, as positive activating emotions, have on perception of control, interest and motivation in achievement situations. The experience of joy implies the feeling of well-being, and is associated with the desire to engage further in related tasks (Ainley \& Ainley, 2011; Pekrun, Elliot, \& Maier, 2006), while hope concerns the cognitive process of pursuing a goal through putting plans in motion and motivating oneself (Feldman \& Kubota, 2015), fostering the sense of personal control and value of learning. Both emotions maintain the interest in the ongoing task.

Results for the emotion word pride suggest that when a person experiences pride in an achievement situation, it is somewhat likely that they want to oppose someone or something. This finding may be explained by distinguishing two different facets of pride suggested by 
recent research (Tracy \& Robins, 2007; Tracy \& Prehn, 2012). Whereas "authentic" pride is associated with feelings of confidence, accomplishment, and self-worth, and is conceptualized in terms of descriptive words such as "accomplished", "triumphant", and "confident" (Tracy \& Robins, 2004), "hubristic" pride has shown to be more associated with arrogance and words such as "cocky" and "conceited". The later facet is thought to be fueled by an inauthentic sense of self (i.e., self-aggrandized self-view), and may motivate behaviors oriented toward attaining dominance, contributing to aggression and hostility (Tracy \& Robins, 2007; Tracy \& Prehn, 2012; Bushman \& Baumeister, 1998). Another possibility is that, as participants were encouraged to think of another person's experience of pride, they were prone to imagine the pride felt by others as hubristic (Tracy \& Robins, 2007). More research must be done to identify what circumstances characterize either facet of pride in an achievement situation.

\section{Positive deactivating emotions}

The CVT of achievement emotions predicts that contentment is induced when the person succeeds at avoiding task-based/intrapersonal incompetence, and that relief is, in turn, elicited when a person succeeds at avoiding anticipated failure (Pekrun et al., 2007). According to this model, positive deactivating emotions are associated with a sense of accomplishment that lowers the need to exert further effort to learn; they may reduce task attention, and may lead to superficial information processing (Pekrun, 2012). However, results of the present study showed that, when a person says he or she felt relief or contentment, it is likely that they were able to concentrate on what was going on (contentment $M d n=7$; relief $M d n=8$ ), wanted to try new and creative ways of approaching the task at hand (contentment $M d n=7$; relief $M d n=7$ ), and it is somewhat likely that they wanted to try harder (contentment $M d n=$ 7; relief $M d n=6$ ). There are at least two possible different explanations for these findings. A conservative view may suggest, in line with Vohs \& Baumeister's (2008) 'extended now' state, that the satisfaction of the desire of success should result in a subsequent strengthening of that desire, shortly after an immediate reduction of desire following success. In this respect, an emotion such as contentment may motivate the desire to put more effort into a task in the long run, after a moment of relaxation. An alternative explanation suggests that the semantic profile in regards to the action tendencies of contentment and relief for the Colombian population may present with cultural differences contradicting what has been predicted by the CVT, which could imply that this population does not experience contentment and relief as deac- 
tivating, but rather activating, emotions. More research has to be done regarding this possibility.

\section{Negative activating emotions}

Negative activating emotions are experienced as unpleasant and have complex effects on performance and engagement (Pekrun et al., 2007). Depending on the circumstances, these emotions can be pervasive for performance and may undermine intrinsic motivation, or they can help with goal attainment by signaling cognitive strain, which motivates to invest more effort in the ongoing task, pay more attention, and make fewer errors (Kahneman, 2011). Below, the most remarkable results for negative activating emotions are discussed.

The case of anger. In the CVT, an example of a situation that elicits anger is an activity that is unpleasant and requires effort and subjective control. This model also proposes that the effects of anger in interest and motivation are complex and ambivalent (Pekrun et al., 2007). Two findings from the present study are of special interest for this emotion, namely, that the anger that occurs in an achievement context may decrease the motivation to pay attention to a given task and produce the desire to do nothing. This evidence is intriguing, since previous research posits that anger may arise when a person who is on the way to a specific goal encounters an obstacle, and this emotion promotes the attempt to remove or overcome the obstacle, in service to attaining the goal (Carver \& Harmon-Jones, 2009). The results shown here suggest otherwise. One reason for this may be that participants could have interpreted anger as a negative outcome-focused emotion, that is, occurring following feedback on a specific achievement task (Elliot \& Pekrun, 2007), thus inferred that the person possibly felt no desire to do anything else after failing to meet their goal, in which case, this emotion could be associated with frustration, as antecedent, and hopelessness, as outcome. In regards to the decrease in motivation to pay attention brought about by anger, at least in the context of sport, although anger may have beneficial consequences for an individual's performance, debilitating effects may be associated either with a lack of energy or resources or an ineffective utilization of resources (Ruiz \& Hanin, 2011), causing the person to 'draw a blank'.

Evidence seems limited for the role of anger in achievement settings apart from situations in athletic performance. Future studies should focus on the effects of anger on motivation and attention in academic, competitive, and professional settings. 
Anxiety. Results corroborate general knowledge that anxiety in achievement settings has motivational components in terms of motivation to avoid failure and impulses to escape from the situation (Pekrun \& Stephens, 2015). In this order of ideas, anxiety seems to trigger ambivalent motivational impulses: while the person may want to run away from the situation, his or her motivation to invest effort to avoid failure, as well as to fulfill their obligation, is strengthened (Pekrun \& Stephens, 2015; Pekrun et al., 2007). The semantic profile of anxiety seems to highlight these ambivalent feelings in order to differentiate between achievement and unspecified general contexts. The findings presented here are different from those of Gentsch et al. (in press), which suggest that the motivation to run away in any direction is more likely to appear in an achievement context than in an unspecified context. They also found a contextual effect in three more features, which was not observed in the present study.

Guilt and shame. These negative emotions are usually correlated and involve selfevaluative judgments of cognitions and actions according to internal standards (Stuewig \& Tangney, 2007). Findings from the present study also show similar semantic profiles for these emotions; however, a few differences can be made. For example, one the results suggests that it is rather unlikely that the person who uses these emotion words to describe an event refers to having aggressive tendencies, both in the achievement and in the unspecified context. These findings are in line with the knowledge that guilt may serve a protective function against aggression in that it is associated with taking responsibility for one's actions and focusing on reparation (Stuewig \& Tangney, 2007). But when it comes to shame, existing literature is more ambivalent. Nevertheless, although shame has been linked to verbal and physical aggression (Stuewig \& Tangney, 2007; Velotti, Elison \& Garofalo, 2014), this relationship seems more likely for shame-prone individuals.

According to the results of this study, it is very likely that the person who experiences shame wanted to stop what they were doing, probably because shame renders individuals more vulnerable to the negative effects of failure and increases the likelihood to show less persistence and effort (Thompson, Altmann \& Davidson, 2004). As for guilt, there is also a motivation to stop the ongoing action. An explanation for this may be that guilt is a response to an undesirable behavior or action that violates social or internal standards (e.g., neglecting a responsibility) (Gruenewald, Dickerson \& Kemeny, 2007). Although this study points out a greater chance for this motivation to arise in a general context than in an achievement context, other emotion components, such as appraisals, should be taken into account in the future to 
explore these differences. The remaining differences suggest that guilt may motivate the person to comply with someone else's wishes, possibly to make up for an inappropriate behavior, but this motivation is not clear in an achievement context.

Frustration and despair. Results suggest that the achievement context has an effect that is similar in the semantic profile of frustration and despair. Both emotions are likely to be aroused by failure and to entail a motivation to oppose someone or something. Differences between the Conditions of this study suggest that the achievement context may mitigate this approach tendency a little. Moreover, the aggressive tendency observed in the semantic profile of despair also seems to be diminished in an achievement context.

Although it is clear that frustration allows to redirect limited attentional resources away from the central task or goal to peripheral features of the information environment that may have become obstacles (Amsel, 1992), there also may be a slight tendency to approach the ongoing task systematically in the achievement context, in part because, as an activating emotion, it may activate efforts to improve performance (Pekrun et al., 2007). The same tendency is observed in the profile of despair. For this emotion, the results suggest that there is slightly more chance for the achievement context to promote permanence in the ongoing task. This possibility is worth exploring in further studies.

\section{Negative deactivating emotions}

As noted by Pekrun (2011), negative deactivating emotions differ from negative activating emotions in that they "may uniformly impair performance by reducing cognitive resources, undermining both intrinsic and extrinsic motivation, and promoting superficial information processing" (p. 31). The results of this study mostly go in hand with the current knowledge about this category of emotions. For example, disappointment is unlikely to motivate engagement, concentration, and overcoming an obstacle, and hopelessness is unlikely to cause a desire to approach a task in new and creative ways, even taking into account the statistically significant differences between Conditions described above. For the emotions boredom and sadness, however, differences between conditions present challenges for ulterior research and, therefore, they will receive more attention in the sections below.

Boredom. This emotion is experienced as unpleasant, as the activity that elicits it acquires negative intrinsic value, and involves a reduction of physiological activation. It corre- 
lates negatively to attention and effort at achievement activities, and motivates the avoiding of engagement (Pekrun, Goetz, Daniels, Stupnisky, \& Perry, 2010). The findings of this study, although in line with previous knowledge about boredom, suggest that there may be a slightly bigger chance that boredom in an achievement situation motivates the desire to try new and creative ways of approaching the task at hand and to try harder; this could possibly be related to an increment in activation as an outcome: as put by Pekrun et al. (2010), "increased activation accompanying prolonged boredom and repetitive activities [...] may result from the investment of mental effort to sustain attention [...] or from anger aroused by situational constraints that prevent escape" (p. 532). The possibility of boredom motivating to change the way in which the activity is performed could be addressed in ulterior research.

The special case of sadness. The interaction between sadness and anger is common (Izard, 1991); one example is that in many situations the experience of sadness activates anger toward oneself or others after an antecedent attribution (see Izard, 1991, for sadness-anger interactions). In an achievement context, anger and sadness are induced more than other achievement emotions following a failure (Peterson, Brown, \& Jun, 2015). Results revealed that, according to its semantic profile, it is likely that sadness motivates the desire to do damage, hit or say something that hurts in an achievement situation, while it is somewhat unlikely in another context.

Another noteworthy finding is that it is more likely that the person experiencing sadness wanted someone else to take the initiative if the emotion occurs in a general context, in comparison with the likelihood of this action tendency appearing in an achievement context. This could be because of situational constraints arising from achievement contexts (e.g., responsibility). However, more information is required in order to explain this result.

The case of surprise. The results revealed that surprise experienced in an achievement context is likely to motivate the person to try new and creative ways of approaching the task at hand. This is in line with the primary function of this emotion, which is "to help prepare the individual to deal effectively with the new or sudden event and with the consequences of this event" (Izard, 1991, p. 180). Furthermore, this finding concurs with research about surprise being associated with curiosity (Ainley, 2007), and probably arising from quick flashes of insight caused by the recognition of appropriate content following the cognitive disequilibri- 
um that occurs in relation to unexpected or novel content during problem solving, reasoning, and comprehension of technical material (Graesser \& D’Mello, 2011).

Results also show that it is somewhat likely that a person who experiences surprise in an achievement context wants to sing and dance, apparently in an association with enjoyment. Overall, results for surprise suggest that, when it is experienced in achievement situations, it relates to curiosity, creative thinking, and enjoyment. These findings represent a novel contribution to those of Soriano, Fontaine, and Scherer (2015) for the semantic profile of surprise.

\section{Conclusion}

The present study investigated how the semantic profiles of achievement emotions differ in relation to context. Despite the limitations - more explicitly presented below-, contextual differences, theoretically, brought about by the evaluation of performance implicated in the achievement situation, were found in the semantic profiles of action tendencies of all the emotions studied; although it seems that the achievement context does not have an equal effect for every emotion, rather, each emotion is affected in a particular way, suggesting that the motivational component of every emotion has a complex relation with context. These findings are different from those presented by Gentsch et al. (in press), which may be due to differences in the semantic profiles of emotion words between the German and Colombian Spanish languages, or because of discrepancies between the methods of analysis used in both studies. A further study should compare the two datasets in order to reliably establish the significant differences. In the discussion section of this article, the most noteworthy differences were presented, along with suggestions on the direction that future research about the semantic profiles relating to behavioral tendencies should take.

Finally, using the AECG questionnaire to understand how people use emotion words to describe their motivation to behave in achievement settings represents a valid supporting tool for the development of valid and reliable studies that explore emotions with accurately defined emotion words, with the ulterior motive of building learning, competitive, and working environments that are sensitive to emotions.

\section{Limitations of this study}


As noted earlier, the present study could not contrast its findings with those of similar studies, with the exception of Gentsch et al. (in press), due to the lacking research on semantic profiles of achievement emotions. In order to compensate for this limitation, results were compared with literature about the motivational components of emotions. Also, discussion only targeted some of the findings and left off the statistically significant differences that were difficult to explain, but that could nevertheless be of use for ulterior research. Another limitation that was noted by some participants at the end of the study sessions was that prompting respondents to think of a situation of "success or failure" is not specific enough; a person could decide to respond to the questionnaire thinking about an experience of success and that answer could be different if they had decided to think about a failure experience. This ambiguity should be taken into account and controlled for in further studies with the AE CoreGRID, possibly by asking participants what kind of situation is on their minds. Another limitation was that even the unspecified context could have been interpreted as an emotional experience in an achievement context, and the present study did not have a way to discriminate for this. Lastly, some participants also expressed that they experienced fatigue because of the duration of the study sessions, this factor may have favored carelessness and response tendency in participants' ratings of different features of the emotion. In an effort to compensate for this limitation, in the present study, participant by word combinations that showed fifty-eight or more times the same response category were removed. In the future, the duration and/or number of response sessions could be modified to reduce fatigue.

\section{Acknowledgments}

We thank GRID directors K. R. Scherer, J. Fontaine, and C. Soriano for granting us permission to translate, adapt, and use the GRID instrument. We also thank C. Soriano for helping with the discussion within the process of backtranslation. Finally, we thank K. Loderer for her guidance and support throughout our study.

\section{References}

Ainley, M. (2007). Being and feeling interested: Transient state, mood, and disposition. In P. A. Schutz, \& R. Pekrun (Eds.), Emotion in education (pp. 147-163). San Diego, CA: Academic Press. 
Ainley, M., \& Ainley, J. (2011). Student engagement with science in early adolescence: The contribution of enjoyment to students' continuing interest in learning about science. Contemporary Educational Psychology, 36(1), 4-12. doi:10.1016/j.cedpsych.2010.08.001

Amsel, A. (1992). Frustration theory: An analysis of dispositional learning and memory. Cambridge: Cambridge University Press.

Bushman, B. J., \& Baumeister, R. F. (1998). Threatened egotism, narcissism, self-esteem, and direct and displaced aggression: Does self-love or self-hate lead to violence? Journal of Personality and Social Psychology, 75(1), 219-229. doi:10.1037/00223514.75.1.219

Carver, C., \& Harmon-Jones, E. (2009). Anger is an approach-related affect: Evidence and implications. Psychological Bulletin, 135(2), 183-204. doi:10.1037/a0013965

Elliot, A. J., \& Pekrun, R. (2007). Emotion in the hierarchical model of approach-avoidance achievement motivation. In P. A. Schutz, \& R. Pekrun (Eds.), Emotion in education (pp. 57-73). San Diego, CA: Academic Press.

Feldman, D. B., \& Kubota, M. (2015). Hope, self-efficacy, optimism, and academic achievement: Distinguishing constructs and levels of specificity in predicting college gradepoint average. Learning and Individual Differences, 37, 210-216. doi:10.1016/j.lindif.2014.11.022

Fontaine, J. J. R., \& Scherer, K. R. (2013). Emotion is for doing: The action tendency component. In J. J. R. Fontaine, K. R. Scherer, \& C. Soriano (Eds.). Components of emotional meaning: A sourcebook (pp. 170-185). New York, NY: Oxford University Press. doi:10.1093/acprof:oso/9780199592746.001.0001

Frijda, N. H., Kuipers, P., \& ter Schure, E. (1989). Relations among emotion, appraisal, and emotional action readiness. Journal of Personality and Social Psychology, 57(2), 212228. doi:10.1037/0022-3514.57.2.212

Gentsch, K., Loderer, K., Soriano, C., Fontaine, J. R. J., Eid, M., Pekrun, R., \& Scherer, K. R. (in press). Effects of achievement contexts on the meaning structure of emotion words. Cognition and Emotion. doi:10.1080/02699931.2017.1287668

González, A., Donolo, D., \& Rinaudo, C. (2009). Emociones académicas en universitarios: su relación con las metas de logro. [Academic emotions in university students: their relations with achievement goals.] Ansiedad y Estrés, 15(2-3), 263-277.

Graesser, A., \& D’Mello, S. K. (2011). Theoretical perspectives on affect and deep learning. In R. A. Calvo, \& S. K. D’Mello (Eds.), New perspectives on affect and learning tech$-351-$ 
nologies. Explorations in the learning sciences, instructional systems and performance technologies (pp. 11-21). Springer Science+Business Media. doi:10.1007/978-1-44199625-1

Gruenewald, T. L., Dickerson, S. S., \& Kemeny, M. E. (2007). A social function for selfconscious emotions: The Social Self Preservation theory. In J.L. Tracy, R.W. Robins, J.P. Tangney (Eds.), The self-conscious emotions: Theory and research (pp. 68-87). New York, NY: The Guilford Press.

Izard, C. E. (1991). The psychology of emotions. New York, NY: Plenum Press.

Johnson-Laird, P. N., \& Oatley, K. (1989). The language of emotions: An analysis of a semantic field. Cognition \& Emotion, 3(2), 81-123. doi:10.1080/02699938908408075

Kahneman, D. (2011). Thinking, fast and slow. Canada: Doubleday Canada.

Loderer, K., Gentsch, K., Pekrun, R., \& Scherer, K. R. (2015, July). Components of achievement emotions - A GRID-based investigation. Paper presented at the 2015 Conference of the International Society for Research on Emotions (ISRE), Geneva, Switzerland.

Mellado, V., Borrachero, A. B., Brígido, M., Melo, L. V., Dávila, M. A., Cañada, F.,... Bermejo, L. (2014). Las emociones en la enseñanza de las ciencias. [Emotions in Science teaching.] Enseñanza de las ciencias, 32(3), 11-36. doi:10.5565/rev/ensciencias.1478

Ortony, A., Clore, G. L., \& Foss, M. A. (1987). The referential structure of the affective lexicon. Cognitive Science, 11(3), 341-364. doi:10.1207/s15516709cog1103_4

Paoloni, P. V., \& Vaja, A. B. (2013). Emociones de logro en contextos de evaluación: un estudio exploratorio con alumnos universitarios. Innovación Educativa, 13(62), 135-159.

Pekrun, R. (2006). The control-value theory of achievement emotions: Assumptions, corollaries, and implications for educational research and practice. Educational Psychology Review, 18(4), 315-341. doi:10.1007/s10648-006-9029-9

Pekrun, R. (2011). Emotions as drivers of learning and cognitive development. In R. A. Calvo, \& S. K. D’Mello (Eds.), New perspectives on affect and learning technologies. Explorations in the learning sciences, instructional systems and performance technologies (pp. 23-39). Springer Science+Business Media. doi:10.1007/978-1-4419-9625-1

Pekrun, R., Elliot, A. J., \& Maier, M. A. (2006). Achievement goals and discrete achievement emotions: A theoretical model and prospective test. Journal of Educational Psychology, 98(3), 583-597. doi:10.1037/0022-0663.98.3.583

Pekrun, R., Frenzel, A. C., Goetz, T., \& Perry, R. P. (2007). The control-value theory of achievement emotions: An integrative approach to emotions in education. In P. A. 
Schutz, \& R. Pekrun (Eds.), Emotion in education (pp. 13-36). San Diego, CA: Academic Press.

Pekrun, R., Goetz, T., Daniels, L. M., Stupnisky, R. H., \& Perry, R. P. (2010). Boredom in achievement settings: Exploring control-value antecedents and performance outcomes of a neglected emotion. Journal of Educational Psychology, 102(3), 531-549. doi:10.1037/a0019243

Pekrun, R., \& Stephens, E. J. (2015). Test anxiety and academic achievement. In J. D. Wright (Ed.), International Encyclopedia of the Social \& Behavioral Sciences (2 ed., Vol. 24, pp. 244-249). Elsevier. doi:10.1016/B978-0-08-097086-8.26064-9

Peterson, E. R., Brown, G. T. L., \& Jun, M. C. (2015). Achievement emotions in higher education: A diary study exploring emotions across an assessment event. Contemporary Educational Psychology, 42, 82-96. doi:10.1016/j.cedpsych.2015.05.002

Ruiz, M. C., \& Hanin, Y. L. (2011). Perceived impact of anger on performance of skilled karate athletes. Psychology of Sport and Exercise, 12(3), 242-249. doi:10.1016/j.psychsport.2011.01.005

Russell, J. R. (1991). Culture and the categorization of emotions. Psychological Bulletin, 110(3), 426-450. doi:10.1037/0033-2909.110.3.426

Sánchez-Rosas, J. (2013). Búsqueda de ayuda académica, autoeficacia social académica y emociones de logro en clase en estudiantes universitarios. [Academic help seeking, social academic self-efficacy and class-related emotions in university students.] Revista Argentina de Ciencias del Comportamiento, 5(1), 35-41.

Scherer, K. R. (2013). Measuring the meaning of emotion words: A domain-specific componential approach. In J. J. R. Fontaine, K. R. Scherer, \& C. Soriano (Eds.). Components of emotional meaning: A sourcebook (pp. 7-30). New York, NY: Oxford University Press. doi:10.1093/acprof:oso/9780199592746.001.0001

Scherer, K. R., Fontaine, J. J. R., \& Soriano, C. (2013).CoreGRID and MiniGRID: Development and validation of two short versions of the GRID instrument. In J. J. R. Fontaine, K. R. Scherer, \& C. Soriano (Eds.). Components of emotional meaning: A sourcebook (pp. 523-541). New York, NY: Oxford University Press. doi:10.1093/acprof:oso/9780199592746.001.0001

Scherer, K. R., Shuman, V., Fontaine, J. J. R., \& Soriano, C. (2013). The GRID meets the Wheel: Assessing emotional feeling via self-report. In J. J. R. Fontaine, K. R. Scherer, \& C. Soriano (Eds.). Components of emotional meaning: A sourcebook (pp. 281-298). 
New York, NY: Oxford University Press. doi:10.1093/acprof:oso/9780199592746.001.0001

Smith, C. A., \& Lazarus, R. S. (1990). Emotion and adaptation. In L. A. Pervin (Ed.). Handbook of personality: Theory and research (1st ed., pp. 609-637). New York, NY: Guilford Press.

Soriano, C., Fontaine, J. R. J., \& Scherer, K. R. (2015). Surprise in the GRID. Review of Cognitive Linguistics, 13(2), 436-460. doi:10.1075/rcl.13.2.07sor

Stuewig, J., \& Tangney, J. P. (2007). Shame and Guilt in Antisocial and Risky Behaviors. In J.L. Tracy, R.W. Robins, J.P. Tangney (Eds.), The self-conscious emotions: Theory and research (pp. 371-388). New York, NY: The Guilford Press.

Thompson, T., Altmann, R., \& Davidson, J. (2004). Shame-proneness and achievement behaviour. Personality and Individual Differences, 36(3), 613-627. doi:10.1016/S01918869(03)00121-1

Tracy, J. L., \& Prehn, C. (2012). Arrogant or self-confident? The use of contextual knowledge to differentiate hubristic and authentic pride from a single nonverbal expression. $\mathrm{Cog}$ nition and Emotion, 26(1), 14-24. doi:10.1080/02699931.2011.561298

Tracy, J. L., \& Robins, R.W. (2004). Show your pride: Evidence for a discrete emotion expression. Psychological Science, 15(3), 194-197. doi: 10.1111/j.09567976.2004.01503008.x

Tracy, J. L., \& Robins, R.W. (2007). The nature of pride. In J. L. Tracy, R.W. Robins, J. P. Tangney (Eds.), The self-conscious emotions: Theory and research (pp. 263-282). New York, NY: The Guilford Press.

Van den Eede, S. J. E., \& Fontaine, J. J. R. (2013). Assessing interindividual differences in emotion knowledge: Exploring a GRID-based approach. In J. J. R. Fontaine, K. R. Scherer, \& C. Soriano (Eds.). Components of emotional meaning: A sourcebook (pp. 299-307). New York, NY: Oxford University Press.

Velotti, P., Elison, J., \& Garofalo, C. (2014). Shame and aggression: Different trajectories and implications. Aggression and Violent Behavior, 19(4), 454-461. doi:10.1016/j.avb.2014.04.011

Vohs, K. D., \& Baumeister, R. F. (2008). Can satisfaction reinforce wanting? A new theory about long-term changes in strength of motivation. In J. Y. Shah \& W. L. Gardner (Eds.), Handbook of motivation science (pp. 373-389). New York: Guilford. 